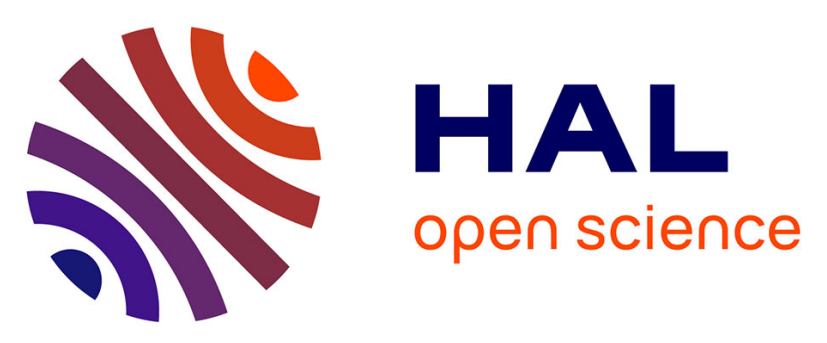

\title{
Towards an analytical formulation for Fluid Structure tank vibration analysis: Modal equivalency using granular materials
}

Sinh-Khoa Nguyen, Pierre-Louis Chiambaretto, M. Charlotte, Philippe Villedieu, Joseph Morlier, Yves Gourinat

\section{To cite this version:}

Sinh-Khoa Nguyen, Pierre-Louis Chiambaretto, M. Charlotte, Philippe Villedieu, Joseph Morlier, et al.. Towards an analytical formulation for Fluid Structure tank vibration analysis: Modal equivalency using granular materials. Engineering Structures, 2018, 177, pp.345-356. 10.1016/j.engstruct.2018.09.077 . hal-01893436

\section{HAL Id: hal-01893436 https://hal.science/hal-01893436}

Submitted on 11 Oct 2018

HAL is a multi-disciplinary open access archive for the deposit and dissemination of scientific research documents, whether they are published or not. The documents may come from teaching and research institutions in France or abroad, or from public or private research centers.
L'archive ouverte pluridisciplinaire HAL, est destinée au dépôt et à la diffusion de documents scientifiques de niveau recherche, publiés ou non, émanant des établissements d'enseignement et de recherche français ou étrangers, des laboratoires publics ou privés. 


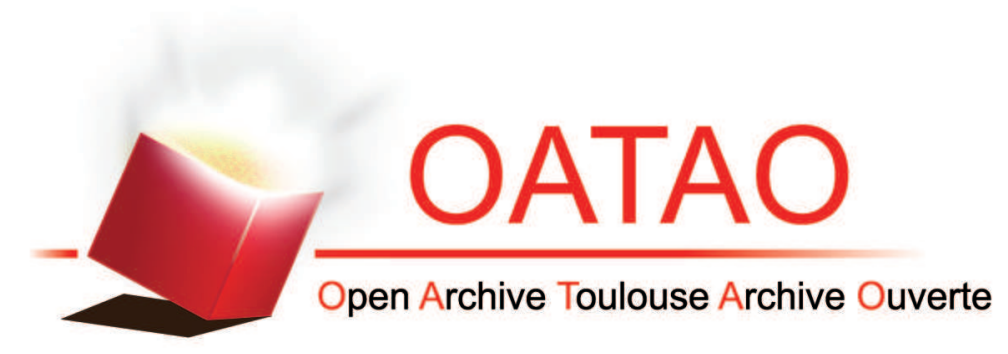

\section{Open Archive Toulouse Archive Ouverte (OATAO)}

OATAO is an open access repository that collects the work of some Toulouse researchers and makes it freely available over the web where possible.

This is an author's version published in: https://oatao.univ-toulouse.fr/20159

Official URL : https://doi.org/10.1016/j.engstruct.2018.09.077

\section{To cite this version :}

Nguyen, Sinh-Khoa and Chiambaretto, Pierre-Louis and Charlotte, Miguel and Morlier, Joseph and Gourinat, Yves and Villedieu, Philippe Towards an analytical formulation for Fluid Structure tank vibration analysis: Modal equivalency using granular materials. (2018) Engineering Structures, 177. 345-356. ISSN 0141-0296

Any correspondence concerning this service should be sent to the repository administrator: 


\title{
Towards an analytical formulation for fluid structure tank vibration analysis: Modal equivalency using granular materials
}

\author{
Sinh-Khoa Nguyen ${ }^{\mathrm{a}}$, Pierre-Louis Chiambaretto ${ }^{\mathrm{a}}$, Miguel Charlotte $^{\mathrm{a}, *}$, Philippe Villedieu ${ }^{\mathrm{b}}$, \\ Joseph Morlier ${ }^{\mathrm{a}}$, Yves Gourinat ${ }^{\mathrm{a}}$

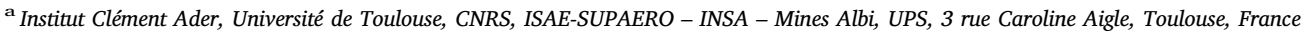 \\ ${ }^{\mathrm{b}}$ DMAE, ONERA, Centre de Toulouse, 2 avenue Edouard Belin, Toulouse, France
}

Keywords:

Vibration analysis

Effective modal equivalences

Cryogenic tank

Granular materials

Homogenization

\begin{abstract}
A B S T R A C T
This paper focuses on a new methodology for substitution of Liquid Hydrogen (LH2) contained in cryogenic tank in vibration analysis by using surrogate granular materials. Our analysis is limited to a 3D tank that is supposed to be fully filled with granular grains and tries to establish a modal equivalence between (tank fully filled with LH2) and (tank fully filled with granular grains) systems. For this, we determine required pre-stresses based on a homogenization technique from properties of grains. After reviewing some important mathematical formulations of vibration and homogenization model, an example of modal equivalence between these two systems is presented. Analytical results are also compared with numerical simulations in order to prove the suitability of the new method.
\end{abstract}

\section{Introduction}

Liquid Hydrogen (LH2) is largely used in cryogenic engines for launchers due to its high efficiency [1]. However, utilization of this fuel raises some critical technical problems linked not only to explosiveness and fugacity, but also to our understanding of the dynamic behaviour of the cryogenic tanks. LH2 is indeed too dangerous and expensive to be performed in vibration tests in laboratory [2]. While for other liquid fuels, surrogate liquids such as water are largely used to study the dynamic behavior of the tank, it is however difficult to apply the same strategy for LH2 due to its very low mass density.

A recent work performed by our research group [3] suggested the idea that pre-stressed grain systems as a surrogate material may possibly help to circumvent the aforementioned experimental issue. While outlining a new methodology for this, these preliminary studies provided indeed good analytical results for two-dimensional structural coupling cases, which tend to support the above hypothesis. Nevertheless, the potential applicability of this approach to more engineering cases of three-dimensional cylindrical cryogenic tanks still remained for investigation. That one constitutes the extension targeted by the present article.

Globally, the approach developed here, and which builds on the one used by Chiambaretto et al. [3], involves two main tasks aimed to define an effective strategy for the substitution of liquid fuel in vibration analysis by using granular materials, as schematized in Fig. 1. In one of the tasks, the vibration of tank-fluid material (TFM) system is considered as one of a tank-solid material (TSM) system while assuming that a modal equivalence between the vibrations of these two different structural/material systems can be found for some frequency bandwidths. In the second task, a modal equivalence between the vibrations of the TSM system and a tank-granular material (TGM) must be found with the help of a homogenization technique. The latter task requires notably determining the suitable pre-pressure that must be applied to an assembly of granular systems - to be modelled as a homogeneous continuum - that achieves the modal frequencies and mode shapes of a cylindrical tank filled with LH2. Besides, as performed before in [3], the aforementioned equivalences are stated by means of a simple and efficient methodology. The strategy and the solutions to the different considered dynamics problems that are notably obtained by RayleighRitz method rely on the five following hypotheses:

- H1: Acoustic effects and viscosity are negligible in the fluid domain (LH2). This assumption is notably based both on a Chiambaretto et al.'s estimate of the Helmholtz number [3] that was found to be $10^{-2}$, and on McCarty's one for the viscosity of LH2 at the storage state [21] that is equal to $120.10^{-7} \mathrm{~kg} / \mathrm{ms}$.

- H2: Pre-stressed pressure is high enough to prevent relative motions between grains.

\footnotetext{
* Corresponding author.

E-mail address: miguel.charlotte@isae.fr (M. Charlotte).
} 


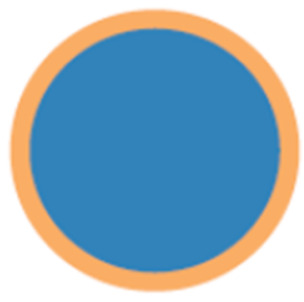

Tank + Fluid

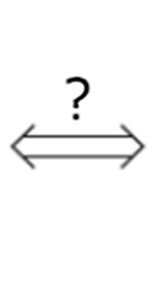

Tank + Homogenized solid

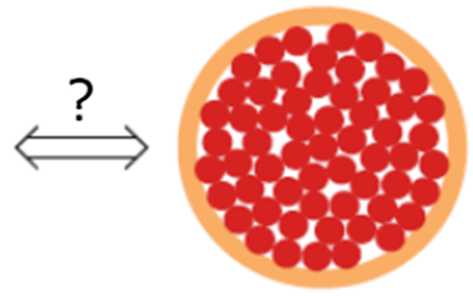

Tank + Granular material

Fig. 1. Modal equivalence between fluid filled beam and grains filled beam using a homogeneous model for granular material [3]

- H3: Granular material can be described as an elastic material with material coefficient depending on pressure.

- H4: Pressure variation during vibration tests is low enough to linearize material coefficients.

- H5: The radial displacements of the mode shape of a free circular beam, of a circular membrane on its free edge and of a beam filled by this circular membrane are the same. The appropriateness of this assumption was checked numerically with COMSOL [3], the simulations pointing out that the modal shapes of a circular beam, of a membrane on free edge, and the coupled system, are very similar.

To our knowledge, the foregoing aim and methodology seem to be new in the literature on Tank - Granular material' coupling systems, where researches concentrate mainly on the storage and flow of grains in silos; the main goal of the proposed methodology is indeed to achieve modal equivalency (over some frequency bandwidths) between a tankfluid material (TFM) system and a tank-solid material (TGM) one so that this last material system can be used as a surrogate material in vibratory tests for launcher tanks.

This paper contains three main sections. First, the general strategy, the mathematical formulations for the vibration analysis and the homogenization model are introduced in the 1 st section. The 2 nd section presents the analytical results for the vibration analyses of an empty tank, a tank fully filled with fluid or else with granular materials. Comparisons between analytical and numerical results are also provided to show the potential of the new methodology. Lastly, in the 3rd section, some important conclusions are drawn and proposals are made in order to find an effective strategy for a surrogate granular material in the future.

\section{Mathematical formulations}

\subsection{Methodology for substitution of Liquid Hydrogen in vibration analysis}

As already stated, the final purpose of the ongoing project is to find a surrogate granular material to substitute the liquid fuel in vibration tests, the concerned liquid fuel being LH2 in our targeted application case. The surrogate material must satisfy the condition that the most representative mode shapes and eigenfrequencies of tank filled with grains are the same as the ones of tank filled with liquid. For our study, the most representative mode shapes and eigenfrequencies of interest are related to the lowest frequencies of vibration, but the criterion of equivalence may be adjusted to other frequency ranges.

From a mathematical point of view, our criterion of equivalence is said to be fulfilled if we can find a granular material solving the following equation

$\frac{K^{T}+K^{G}}{M^{T}+M^{G}}=\frac{K^{T}}{M^{T}+M^{F}}$

with

- $K^{T}, M^{T}$ : respectively the modal stiffness and the modal mass of the tank.

- $K^{G}, M^{G}$ : respectively the modal stiffness, the modal mass of the granular assembly.

$-M^{F}$ : modal mass added by the fluid.

- Based on this idea, the following scheme is proposed in order to find the required pre - stress value for each vibration mode.

Step 1: Determine Modal shapes and Eigen frequencies of TFM system as targeted value for TSM system

\begin{tabular}{|c|}
\hline \multicolumn{1}{|c|}{$\downarrow$} \\
Step 2: Identify the parameters of an elastic homogenization model from an \\
oedometric test. After this step, TGM system is considered as TSM system
\end{tabular}




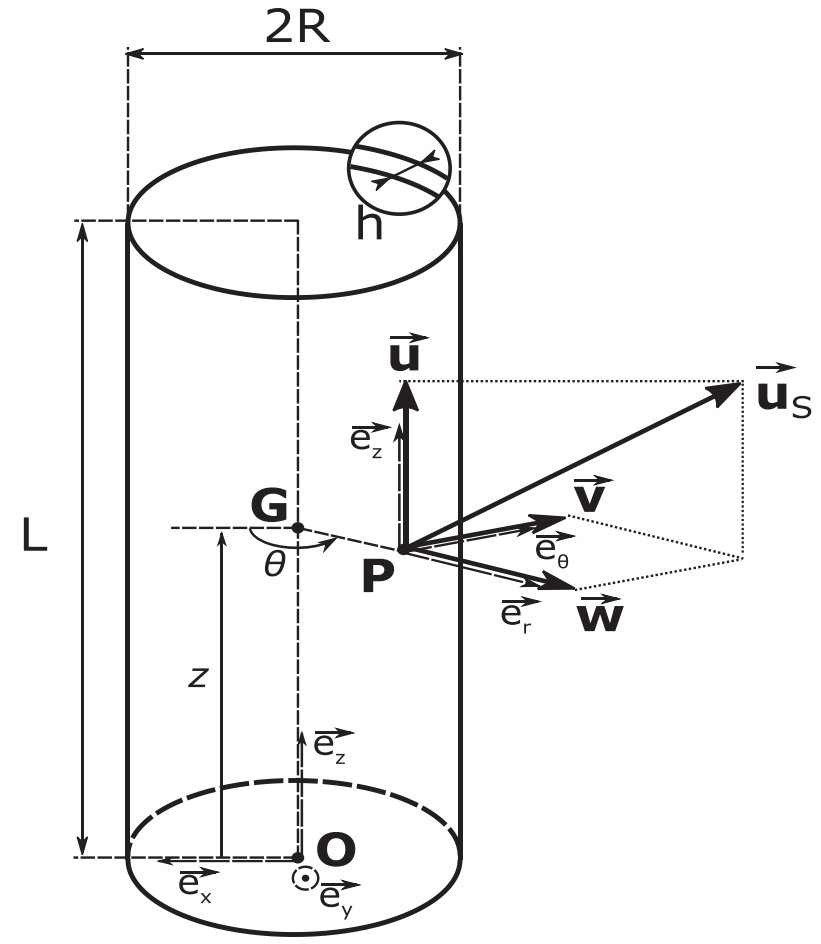

Fig. 2. Geometry of a 3D shell.

Details in this scheme will be demonstrated by an example in Section 3.

2.2. Radial vibrations of empty tanks, tanks filled with LH2, and tanks filled with grains

\subsubsection{Vibration of empty tank}

Within our dynamic modelling, the cryogenic tank is considered as a thin shell structure. Donnell - Mushtari's thin shell theory is used in all our analyses in order to determine modal shapes and eigenfrequencies of lobed modes. For illustration, Fig. 2 shows a structural instance of circular cylindrical shells with its coordinate system. Here $\mathrm{R}$ is the radius of the circular cylindrical shell, $h$ is the thickness, $L$ is the length, $\theta$ is the angle with respect to the vertical axis, $z$ is the axis along its length, and finally $u, v$, and $w$ are the displacements in the $z, \theta$, and $r$ directions, respectively, $r$ is the distance from the middle surface to an arbitrary point on the shell.

According to Leissa [4], the generalized modal mass and stiffness of such a cylindrical shell can be expressed respectively as kinetic and potential energies:

$M_{i j}^{T}=\rho \int_{0}^{L} \int_{0}^{2 \pi} \int_{\frac{-h}{2}}^{\frac{h}{2}}\left(\dot{u}_{i j}^{2}+\dot{v}_{i j}^{2}+\dot{w}_{i j}^{2}\right) R d \theta d z d r$

$K_{i j}^{T}=\int_{0}^{L} \int_{0}^{2 \pi} \int_{\frac{-h}{2}}^{\frac{h}{2}}\left(\sigma_{z} \varepsilon_{z}+\sigma_{\theta} \varepsilon_{\theta}+\sigma_{z \theta} \varepsilon_{z \theta}\right) R d \theta d z d r$

Three components of displacement field are defined as follows:

$u_{i j}=A_{i j} \cos (i \theta) \cos \left(\frac{j \pi z}{L}\right)$

$v_{i j}=B_{i j} \sin (i \theta) \sin \left(\frac{j \pi z}{L}\right)$

$w_{i j}=C_{i j} \cos (i \theta) \sin \left(\frac{j \pi z}{L}\right)$

Here, $i$ denotes the lobes following the circumference and $j$ denotes the lobes in longitudinal direction. Parameters A, B and C are identified from equations detailed in the Appendix A.

The strain tensor is defined following Donnell-Mushtari's shell theory [4] like

$\varepsilon_{z}=\frac{\partial u}{\partial z}-r \frac{\partial^{2} w}{\partial z^{2}}$

$\varepsilon_{\theta}=\frac{1}{R} \frac{\partial v}{\partial \theta}+\frac{w}{R}-\frac{r}{R^{2}} \frac{\partial^{2} w}{\partial \theta^{2}}$

$\varepsilon_{z \theta}=\frac{\partial v}{\partial z}+\frac{1}{R} \frac{\partial u}{\partial \theta}-\frac{2 r}{R} \frac{\partial^{2} w}{\partial z \partial \theta}$

and the stress tensor is determined with the help of Hooke's linear elastic law like

$\sigma_{z}=\frac{E}{1-\vartheta^{2}}\left(\varepsilon_{z}+\vartheta \varepsilon_{\theta}\right)$

$\sigma_{\theta}=\frac{E}{1-\vartheta^{2}}\left(\varepsilon_{\theta}+\vartheta \varepsilon_{z}\right)$

$\sigma_{\theta z}=\frac{E}{2(1+\vartheta)} \varepsilon_{z \theta}$

\subsubsection{Fluid - structure interaction}

In this work, the tank is assumed fully filled so that sloshing effects can be neglected. In 2D case, each slice of tank can be considered as a circular beam. With the presence of a non-compressible fluid, the mode shapes for each mode remain the same as for the beam without fluid; however the frequency decreases due to the inertia added by fluid $[5,17,18]$. This phenomenon can be decreased by an added mass due to the fluid on each mode. In the case of lobed modes, this added mass by unit of length is defined by:

$M_{a(2 D)}^{F}=\left(F_{i j}^{w}(z)\right)^{2} \frac{\rho_{F} \pi R^{2}}{i}$

Here, $F_{i j}^{w}(z)=C \cdot \sin \left(\frac{j \pi z}{L}\right)$ denotes the amplitude of radial motion which depends on longitudinal position of 2D tank's slice. It should be noted that $F_{i j}^{w}(z)$ has already been described in the previous section as the radial displacement of tank.

The added mass by fluid in 3D case can be considered as the integration of $2 \mathrm{D}$ slice along its length due to the absence of viscosity

$M_{i j}^{F}=\int_{0}^{L} M_{a(2 D)}^{F} \cdot\left(F_{i j}^{w}(z)^{2} d z=\int_{0}^{L}\left(\left(C \cdot \sin \left(\frac{j \pi z}{L}\right)\right)\right)^{2} \cdot \frac{\rho_{F} \pi R^{2}}{i} d z\right.$

Each eigenfrequency of whole TFM system can be found then according to the following equation

$f_{i j}^{T F}=\frac{1}{2 \pi} \sqrt{\frac{K_{i j}^{T}}{M_{i j}^{T}+M_{i j}^{F}}}$

where

- $M_{i j}^{T}+M_{i j}^{F}$ : effective modal mass for the mode $i j$ of the TFM system. - $K_{i j}^{T}$ : effective modal stiffness for that mode $i j$.

2.2.3. Interaction between granular solid and tank in the vibration analysis

We now consider the granular assembly as a continuum solid whose important mechanical properties such as Young's modulus, Poisson's ratio and mass density are determined with the help of a homogenization model.

Following the previous research by Chiambaretto et al. [3], in 2D case, the vibration of homogenized granular material surrounded by a circular beam is considered as in-plane vibration of a membrane. Important mechanical properties of a "granular-membrane" are the Young's modulus, the Poisson's ratio and the mass density denoted respectively as $\left(E^{G}, \vartheta^{G}, \rho^{G}\right)$.

The modal mass and the modal stiffness of the "granular- 
membrane" are determined from the equations proposed by Chiambaretto et al. [3]

$$
\begin{aligned}
M_{i}^{G(2 D)}= & \int_{0}^{1} \pi \rho^{M(G)} \xi R^{2}\left(U_{r}^{2}(\xi)+U_{\vartheta}^{2}(\xi)\right) d \xi \\
K_{i}^{G(2 D)}= & \int_{0}^{1} \frac{\pi E}{1-\vartheta^{2}} \xi\left\{\dot{U}_{r}^{2}+2 \vartheta U_{r}\left(\frac{U_{r}}{\xi}+i \frac{U_{\theta}}{\xi}\right)+\left(\frac{U_{r}}{\xi}+i \frac{U_{\vartheta}}{\xi}\right)^{2}\right. \\
& \left.+\frac{1-\vartheta}{2}\left(-i \frac{U_{r}}{\xi}+\dot{U}_{t}-\frac{U_{t}}{\xi}\right)^{2}\right\} d \xi
\end{aligned}
$$

with $U_{r}, U_{\theta}, U_{r}, \dot{U}_{\theta}$ are defined in [3].

In $3 \mathrm{D}$, mechanical properties in vibration are supposed to be considered as integration of $2 \mathrm{D}$ slice along the length of tank with a sinus function.

The modal mass and modal stiffness of solids inside the tank are determined by:

$$
\begin{aligned}
M_{i j}^{G(3 D)}= & \int_{0}^{L} \int_{0}^{1} \pi \rho^{M(G)} \xi R^{2}\left(U_{r}^{2}(\xi, z)+U_{\vartheta}^{2}(\xi, z)\right) d \xi d z \\
K_{i j}^{G(3 D)}= & \int_{0}^{L} \int_{0}^{1} \frac{\pi E}{1-\vartheta^{2}} \xi\left\{\dot{U}_{r}^{2}+2 \vartheta U_{r}\left(\frac{U_{r}}{\xi}+i \frac{U_{\vartheta}}{\xi}\right)+\left(\frac{U_{r}}{\xi}+i \frac{U_{\vartheta}}{\xi}\right)^{2}\right. \\
& \left.+\frac{1-\vartheta}{2}\left(-i \frac{U_{r}}{\xi}+\dot{U}_{t}-\frac{U_{t}}{\xi}\right)^{2}\right\} d \xi d z
\end{aligned}
$$

with

$$
\begin{aligned}
& -U_{r}(r, z)=U_{r}(r) \sin \left(\frac{j \pi z}{L}\right) \\
& -U_{\theta}(r, z)=U_{r}(r) \sin \left(\frac{j \pi z}{L}\right) \\
& -\dot{U}_{r}(r, z)=\dot{U}_{r}(r) \sin \left(\frac{j \pi z}{L}\right) \\
& -\dot{U}_{\theta}(r, z)=\dot{U}_{\theta}(r) \sin \left(\frac{j \pi z}{L}\right) \\
& -\xi=\frac{r}{R} .
\end{aligned}
$$

The 2D-case displacement field is detailed in Appendix B.

In those formulas, the superscripted character " . " denotes the differential of the displacements with respect to radial direction of membrane.

Finally, the first frequencies of the TGM system are determined as follows:

$f_{i j}^{T G}=\frac{1}{2 \pi} \sqrt{\frac{K_{i j}^{T}+K_{i j}^{G}}{M_{i j}^{T}+M_{i j}^{G}}}$

where

$-M_{i j}^{T}+M_{i j}^{G}$ : effective modal mass for the mode $i j$; of the TGM system $-K_{i j}^{T}+K_{i j}^{G}$ : effective modal stiffness for that mode $i j$.

\subsection{Vibration of tank in flexion mode}

To characterize the effective flexural modes of the empty tank as well as the TGM and TFM systems, the flexural modes are modeled as a

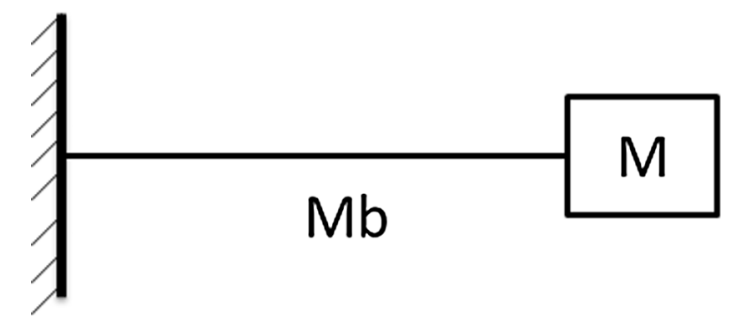

Fig. 3. Clamped - free beam with a mass at the end.
Timoshenko's beam. Each system is modeled as a clamped - free beam which carries a finite mass at the free end as illustrated on Fig. 3.

In general, the eigenfrequencies and eigen-mode shapes along the longitudinal direction of the beam are determined from differential equations proposed by Brutch and Mitchell [4]

$E I \frac{\partial^{2} \varphi}{\partial z^{2}}+K A G\left(\frac{\partial y}{\partial z}-\varphi\right)-\rho I \frac{\partial^{2} \varphi}{\partial t^{2}}=0$

$\rho A \frac{\partial^{2} y}{\partial t^{2}}-K A G\left(\frac{\partial^{2} y}{\partial z^{2}}-\frac{\partial \varphi}{\partial z}\right)=0$

and boundary conditions that are specified in Appendix C.

These equations involve notably the following material and geometrical constants:

- A: cross sectional area of beam $\left(\mathrm{m}^{2}\right)$

- E: Young's modulus of beam $(\mathrm{Pa})$

- $G$ : shear modulus (Pa). $G=\frac{E}{2(1+\vartheta)}$ with $\vartheta$ as the Poisson's ratio.

- I: moment of inertia $\left(\mathrm{m}^{4}\right)$.

- $L$ : length of beam (m).

- Y: deflection of beam's central line

$-\varphi$ : slope due to bending.

$-K$ : factor depending on shape of cross - section.

The solutions to the differential equations given in Eqs. (24) and (25) are found to be like

$y=Y(z) \cos (\omega t)$

$\varphi=\varphi(z) \cos (\omega t)$

with the modal shapes

$Y(z)=C_{1} \cosh \left(b \alpha \frac{z}{L}\right)+C_{2} \sinh \left(b \alpha \frac{z}{L}\right)+C_{3} \cos \left(b \beta \frac{z}{L}\right)+C_{4} \sin \left(b \beta \frac{z}{L}\right)$

$\varphi(z)=C_{1}^{\prime} \sinh \left(b \alpha \frac{z}{L}\right)+C^{\prime}{ }_{2} \cosh \left(b \alpha \frac{z}{L}\right)+C^{\prime}{ }_{3} \sin \left(b \beta \frac{z}{L}\right)+C^{\prime}{ }_{4} \cos \left(b \beta \frac{z}{L}\right)$

Here, the following non - dimensional variable is introduced

$b=L^{2} \omega \sqrt{\frac{1}{E I} \rho A}$

The related natural frequencies of beam are found by solving the ensuing equation

$$
\begin{aligned}
& \frac{\alpha^{2}+S^{2}}{\alpha}\left(R_{3} R_{4}^{\prime}-R_{3}^{\prime} R_{4}+R_{4} R_{1}^{\prime}-R_{1} R_{4}^{\prime}\right) \\
& \quad+\frac{\beta^{2}-s^{2}}{\beta}\left(R_{2} R_{3}^{\prime}-R_{2}^{\prime} R_{3}+R_{1} R_{2}^{\prime}-R_{2} R_{1}^{\prime}\right)=0
\end{aligned}
$$

the parameters $\alpha, \beta, R_{1}, R_{2}, R_{3}, R_{4}, R_{1}^{\prime}, R_{2}^{\prime}, R_{3}^{\prime}, R_{4}^{\prime}$ being also specified in the Appendix (A3).

In the application for the TFM (i.e. tank-fluid) and TGM (i.e. tankgranular) systems, the Eqs. (22) and (23) mainly require explicit values for the productsEI, $\rho A, K A G$ and $\rho I$ but not necessary for $E, I, \rho, A$, $K, G$.

In the case of the tank fully filled with fluids, we suppose that the embedded fluid does not contribute to the global stiffness of the TFM system but to the global inertia. Thus, the following mechanical properties are calculated

$E I=E_{T} \cdot \frac{\pi}{4}\left(R_{\text {ext }}^{4}-R_{i n}^{4}\right)$

$\rho A=\rho_{T} . \pi\left(R_{\text {ext }}^{2}-R_{\text {in }}^{2}\right)+\rho_{f} \cdot \pi\left(R_{\text {in }}^{2}\right)$

$M_{T F}=L \rho A$ 
In case of the tank filled with grains, we suppose that the embedded grains contributes to both the global stiffness and inertia of the TGM, what implies the following mechanical properties

$E I=E_{T} \cdot \frac{\pi}{4}\left(R_{e x t}^{4}-R_{i n}^{4}\right)+E_{G} \cdot \frac{\pi}{4}\left(R_{i n}^{4}\right)$

$\rho A=\rho_{T} \cdot \frac{\pi}{2}\left(R_{\text {ext }}^{2}-R_{\text {in }}^{2}\right)+\rho_{G} \cdot \frac{\pi}{2}\left(R_{\text {in }}^{2}\right)$

$M_{T G}=L \rho A$

Besides, the term $K A G$ in Eq. (22) is substituted by:

$K A G=K_{T} A_{T} G_{T}+K_{G} A_{G} G_{G}$

with:

$K_{T}$ :shear factor for the section of tank (in form of a hollow circle) [7]

$K_{T}=\frac{6\left(1+\vartheta_{T}\right)\left(1+m^{2}\right)^{2}}{\left(7+6 \vartheta_{T}\right)\left(1+m^{2}\right)^{2}+\left(20+12 \vartheta_{T}\right) m^{2}}$

where $m=\frac{R_{\text {in }}}{R_{\text {ext }}}$ and $\vartheta_{T}$ is the Poisson's ratio of the tank material

$K_{G}$ : shear factor for the section de granular solid (in form of a circle) [7]:

$K_{G}=\frac{6\left(1+\vartheta_{G}\right)}{7+\vartheta_{G}}$

where $\vartheta_{G}$ is the Poisson's ratio of the homogenized granular material

- $A_{T}$ : cross sectional area of the tank

- $A_{G}$ : cross sectional area of granular solid inside the tank

- $G_{T}$ : shear modulus of the tank's constitutive material

$-G_{G}$ : shear modulus of the homogenized granular material.

Those formulas will be used in Section 3.3 to characterize the eigenfrequencies that are compared with numerical simulations of the tank filled with different liquids, including LH2, or grains.

\subsection{Generality on the homogenization model}

As we can infer from the mathematical formulations mentioned in Sections 2.2 and 2.3, the eigenfrequencies of TGM system depend on both the overall stiffness (ie. the global Young's modulus and Poisson's ratio) and the mass density of the homogenized granular assembly. Thus, it is important to select a suitable homogenization process that relates the micro-mechanical properties of the grains to the required properties.

In general, a sample of granular materials contains a lot of grains with different sizes, morphologies and stiffnesses. The global behavior of the granular sample depends on the properties and arrangement of these grains in the system. The interaction between two grains of the granular system is defined by contact laws. In the previous works by $[3,8]$, the contact law proposed by Hertz and Mindlin $[9,10]$ was used in a DEM simulation in order to model a laboratory test, whilst, in our modeling, global mechanical properties of the granular system are required. In literature, there are several homogenization approaches in order to estimate the macroscopic elastic mechanical properties of granular assembly. In this paper, we use an approach proposed by Emeriault and Cambou [11].Their formulas for the global Poisson's ratio and Young's modulus are determined from the shear modulus and Poisson's ratio of the grains like

$\vartheta_{G}=\frac{2\left(1-\vartheta_{m}\right)(5-10 \mu)+2\left(5-4 \vartheta_{m}\right) \mu^{2}}{2\left(1-\vartheta_{m}\right)(20-20 \mu)+4\left(5-4 \vartheta_{m}\right) \mu^{2}}$

$E_{G}=E_{0} \frac{1-\vartheta_{m}}{2\left(1-\vartheta_{m}\right)(1-\mu)+\frac{4}{5}\left(5-4 \vartheta_{m}\right) \mu^{2}}$ with

$E_{0}=\left(\frac{G_{m} N \bar{D}^{3}}{\sqrt{6}\left(1-\vartheta_{m}\right)}\right)^{\frac{2}{3}} \cdot \sigma_{M}^{\frac{1}{3}}$

In these expressions

- $\vartheta_{m}, G_{m}$ are respectively Poisson's ratio and shear modulus of the grains

- $\sigma_{M}$ is the mean stress defined by $\sigma_{M}=\frac{1}{3} \operatorname{tr}(\sigma)$

- $\bar{D}$ is the average diameter of grains

$-N$ is the average number of contacts in one unity of volume, this operator is defined by the formula $N=\frac{Z \cdot n}{2 V}$ with $n$ is the total number of grains, $V$ is the volume of granular assembly, $Z$ is the coordination number defined as the average number of contact per particle. This parameter characterizes the local arrangement of grains in the system. Many studies in literature show that there is a relation between the coordination number $Z$ and the void ratio $e$ of a given granular materials [12]. Some empirical models were deduced to relate these two important parameters $[13,14]$, In this paper, we attempt to use the model proposed by Field [15]:

$Z=\frac{12}{1+e}$

- $\mu$ represents the fraction of the deviatoric stress tensor supported by the normal components of contact forces. This parameter may vary from 0 to 1 and is identified by curve-fitting technique with an oedometric test.

\section{Analytical results and comparison with numerical simulations}

3.1. Modeling the oedometric test for the evolution of Young's modulus and mass density

The TGM coupling needs to specify the effective mechanical properties of granular materials. These properties are identified from an oedometric test. In this section, we attempt to model the oedometric test performed by [3] with the homogenization formulas proposed in Section 2.4. The dimension and mechanical properties of grains related to this test are provided in the Appendix D. By supposing that the Poisson's ratio of homogenized media is equal to 0.275 we found by curve-fitting technique that $\mu=0.3$. The modeling and experimental results for the behavior of granular materials in terms of axial stress and strain are presented in Fig. 4.

During the oedometric loading, the mass density of granular material increases, given that the total mass of solid grains is constant and the total volume of whole sample decreases. The Young's modulus of granular media depends not only on grain stiffness but also on mean pressure applied on material; this relation is described with formulas

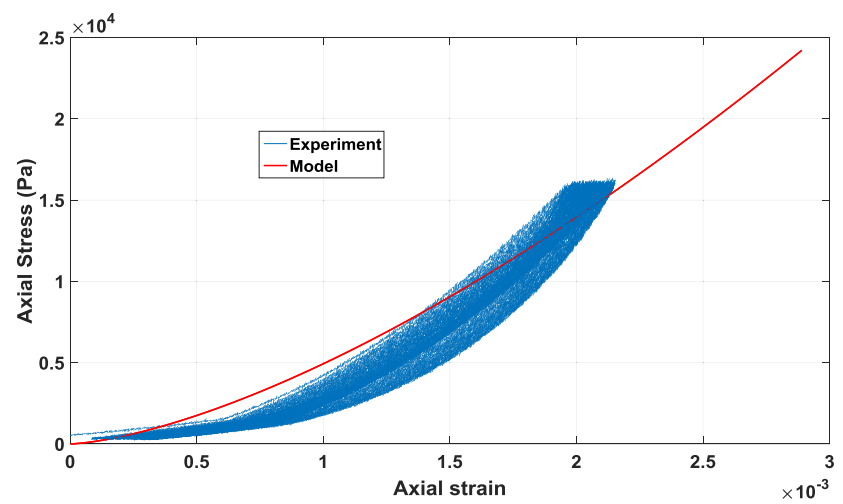

Fig. 4. Experimental and analytical results modeled by proposed homogenization law. 


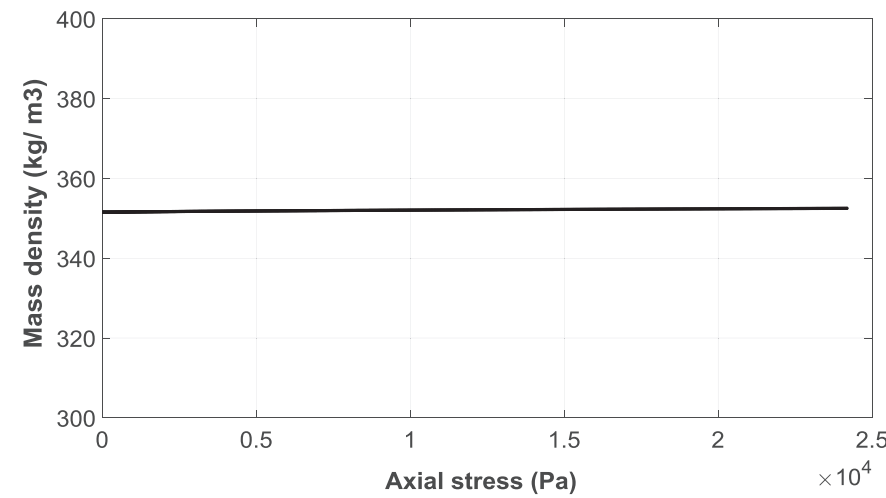

(a)

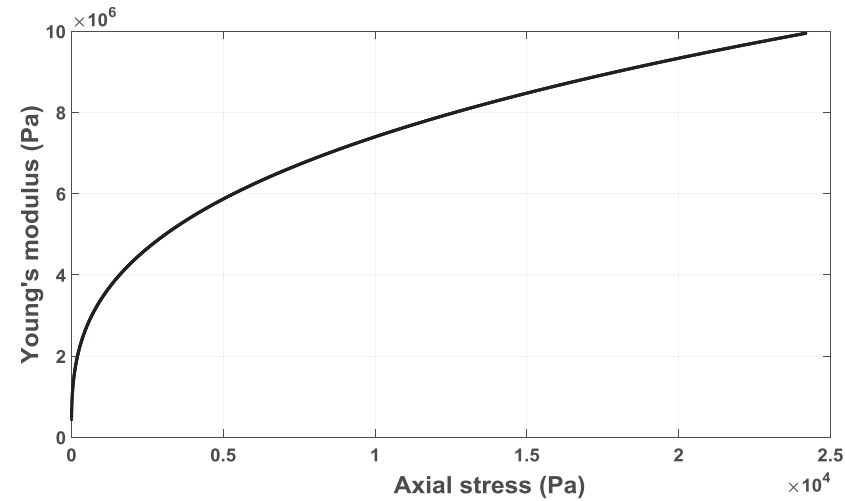

(b)

Fig. 5. Evolutions of (a) the mass density and (b) the Young's modulus of granular assembly during the compression test.

Table 1

Dimension and mechanical properties of tank.

\begin{tabular}{ll}
\hline External radius & $0.1 \mathrm{~m}$ \\
Internal radius & $0.097 \mathrm{~m}$ \\
Thickness & $0.003 \mathrm{~m}$ \\
Young's modulus & $3.3 \mathrm{Gpa}$ \\
Poisson's ratio & 0.45 \\
Mass density & $1190 \mathrm{~kg} \mathrm{~m}^{-3}$ \\
\hline
\end{tabular}

(39)-(41). Thus, during a compression test, Young's modulus of material increases. These evolutions of mass density and Young's modulus in terms of axial stress are illustrated in Fig. 5a and b.

By observing Fig. 5b, we could also deduce that Young' modulus of the whole granular assembly evolves enormously during compression. In detail, this mechanical property increases from 0 to $10 \mathrm{Mpa}$ when the axial stress is increased progressively from 0 to $25 \mathrm{kPa}$. By contrast, we observe on Fig. 5a that the mass density of material remains almost constant during the oedometric test since this property increases only $0.2 \%$ from its initial value (from $351.5 \mathrm{~kg} / \mathrm{m}^{3}$ to $352.5 \mathrm{~kg} / \mathrm{m}^{3}$ ). By virtue of these facts, we can conclude that the eigenfrequency for each mode of vibration of the TGM system increases during the compression. This idea is essential for a new methodology to substitute LH2 in vibration analyses which will be presented in the forthcoming sections.

\subsection{Analytical results and comparison with numerical simulations for the radial vibrations}

This section presents the analytical results and comparison with numerical simulations done with the help of COMSOL for the different couplings, ie. TFM and TGM systems, and for the different lobed- and flexural- modes.

\subsubsection{Analytical results of the vibration analysis for the TFM system}

In this section, we attempt to find the eigenfrequencies of tank in radial vibration (lobed modes). The considered tank is a polycarbonate cylinder with an external radius of $100 \mathrm{~mm}$, a thickness of $3 \mathrm{~mm}$ and $700 \mathrm{~mm}$ of length. Polycarbonate was chosen for its transparency allowing an external determination of the packing fraction. Geometry and mechanical properties of tanks are described in Table 1. The upper bound of tank is covered with an aluminium disk with a thickness of $1 \mathrm{~cm}$, total weight of the disk is $0.8482 \mathrm{~kg}$.

All our forthcoming analyses suppose that the elastic limit of considering granular material is found at $150 \mathrm{kPa}$. In reality, compression tests need to be realized in order to find this yield. LH2.

The tank is assumed to be fully filled with different fluids including

The analytical results were found and compared with numerical results done with the help of COMSOL [16]. Two finite element method

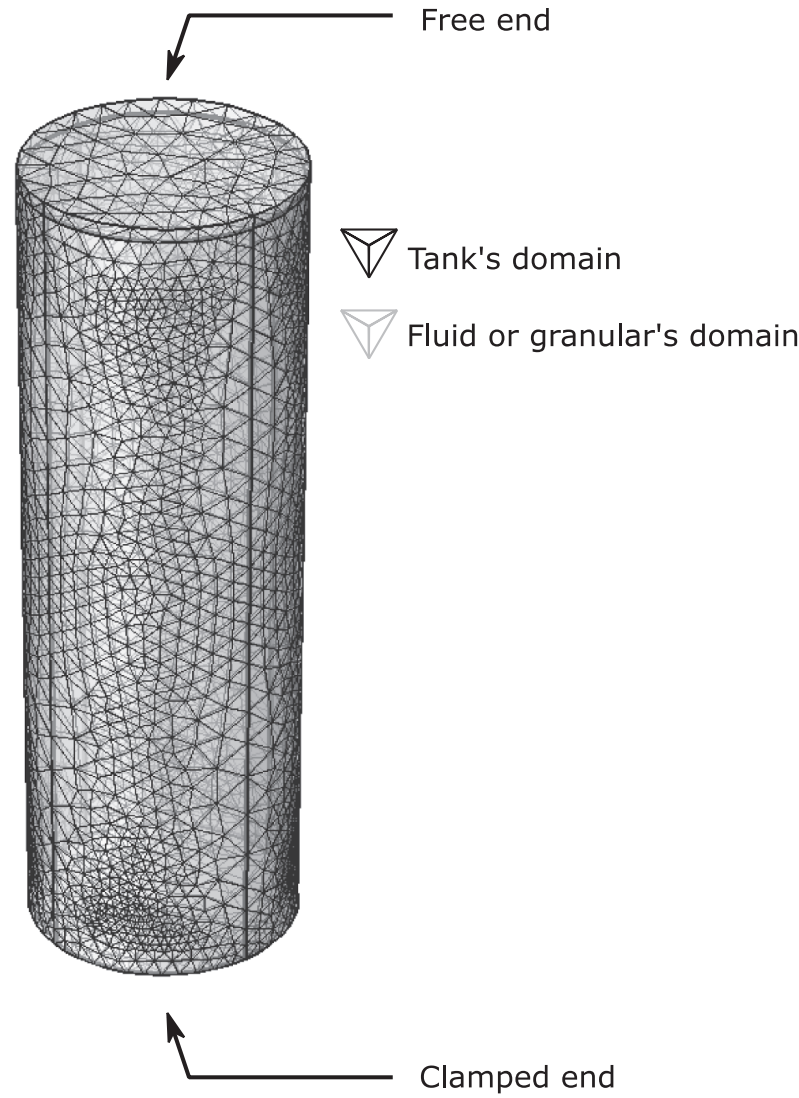

Fig. 6. Numerical model in COMSOL for tank filled with fluid (TFM) system.

(FEM) models have been realized using 2nd order tetrahedral elements. The first one models the empty tank and the second one models the tank fully filled with fluid system. The tank is clamped at the bottom. Geometry and meshing for TFM are shown in the Fig. 6 .

In the fluid domain the variable used is the pressure. The three equations govern the behaviour and the coupling $[5,17,18,19]$.

$\left\{\begin{array}{c}\Delta p=0 \\ \sigma \vec{n}=-p \vec{n} \quad \text { in the fluid domain } \\ \vec{\nabla} p \cdot \vec{n}=\rho_{F} \omega^{2} \vec{u} \cdot \vec{n}\end{array}\right.$ on the boundary with the structure

In the numerical model of the coupling system, the number of degrees of freedom is 137316 . The eigenfrequency values of this system are archived by natural frequency analysis in COMSOL. Monolithic method is used to solve the fluid - structure interaction problem. 
Table 2

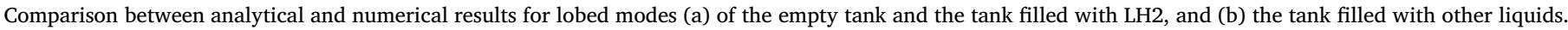

\begin{tabular}{|c|c|c|c|c|c|c|c|}
\hline & & \multicolumn{3}{|l|}{ Empty tank } & \multicolumn{3}{|l|}{$\rho_{F}=72\left(\mathrm{~kg} \mathrm{~m}^{-3}\right)$} \\
\hline & & Numerical (Hz) & Analytical (Hz) & $(\%)$ & Numerical (Hz) & Analytical (Hz) & (\%) \\
\hline \multicolumn{8}{|l|}{ (a) } \\
\hline \multirow[t]{3}{*}{$\mathrm{j}=1$} & $i=2$ & 219 & 236.98 & 8.21 & 165.1 & 178.10 & 7.87 \\
\hline & $i=3$ & 232.7 & 242.9 & 4.38 & 184.4 & 193.40 & 4.88 \\
\hline & $i=4$ & 393 & 417.55 & 6.25 & 322.7 & 346.40 & 7.34 \\
\hline \multirow[t]{3}{*}{$j=2$} & $i=2$ & 475.8 & 491.01 & 3.2 & 362.4 & 369.23 & 1.88 \\
\hline & $\mathrm{i}=3$ & 348.1 & 334.66 & 3.86 & 278.9 & 266.57 & 7.41 \\
\hline & $\mathrm{i}=4$ & 436.5 & 450.45 & 3.2 & 360.5 & 373.77 & 3.68 \\
\hline \multirow[t]{5}{*}{$\mathrm{j}=3$} & $\mathrm{i}=2$ & 781.2 & 792.99 & 1.51 & 600.6 & 596.44 & 1.03 \\
\hline & $i=3$ & 530.8 & 510.25 & 3.87 & 429.1 & 406.55 & 5.26 \\
\hline & $\mathrm{i}=4$ & 525.8 & 530.25 & 0.85 & 437.9 & 440.87 & 0.68 \\
\hline & & \multicolumn{3}{|c|}{$\rho_{F}==2000\left(\mathrm{~kg} \mathrm{~m}^{-3}\right)$} & \multicolumn{3}{|c|}{$\rho_{F}=5000\left(\mathrm{~kg} \mathrm{~m}^{-3}\right)$} \\
\hline & & Numerical (Hz) & Analytical (Hz) & $(\%)$ & Numerical (Hz) & Analytical (Hz) & (\%) \\
\hline \multicolumn{8}{|l|}{ (b) } \\
\hline \multirow[t]{3}{*}{$\mathrm{j}=1$} & $i=2$ & 46.32 & 50.09 & 8.14 & 29.69 & 32.11 & 8.16 \\
\hline & $i=3$ & 55.8 & 58.85 & 5.47 & 35.32 & 37.89 & 7.29 \\
\hline & $\mathrm{i}=4$ & 104.8 & 113.29 & 8.1 & 67.78 & 73.29 & 8.61 \\
\hline \multirow[t]{3}{*}{$\mathrm{j}=2$} & $\mathrm{i}=2$ & 102.9 & 103.87 & 0.94 & 66.06 & 66.59 & 0.9 \\
\hline & $i=3$ & 85.05 & 81.16 & 4.57 & 54.77 & 52.26 & 4.58 \\
\hline & $\mathrm{i}=4$ & 117.7 & 122.30 & 3.91 & 76.11 & 79.12 & 3.95 \\
\hline \multirow[t]{3}{*}{$\mathrm{j}=3$} & $\mathrm{i}=2$ & 172.6 & 167.83 & 2.76 & 110.7 & 107.60 & 2.8 \\
\hline & $i=3$ & 132.2 & 123.83 & 6.3 & 85.15 & 79.74 & 6.35 \\
\hline & $i=4$ & 144.0 & 144.06 & 0.4 & 93.18 & 93.20 & 0.2 \\
\hline
\end{tabular}

Analytical and numerical results are compared in the Table $2 \mathrm{a}$ and $\mathrm{b}$.

A good agreement between analytical and numerical results was found. It shows the suitability of the analytical tool for the shell theory used and hypothesis for interaction between fluid and structure. The observed difference between analytical and numerical results comes from the shell theory (in this case, it is Donnell-Mushtari's theory), however, more complex theories may give a better agreement between two approaches.

\subsubsection{Analytical results of vibration analysis and comparison to numerical simulation for TGM system}

By applying the proposed methodology in Section 2.1 and analytical formulations in Sections 2.2 and 2.4, we can determine the required pre - stresses applied to granular assembly in order to substitute LH2 in vibration analysis. The required axial pre-stress for each mode is determined as intersection of the frequency - axial stress curve of the TGM system and the expected frequency of the TFM system. Here are examples for the modes $(i, j)=(2,1),(2,2)$ and $(2,3)$.

By observing Fig. 7, we could deduce that we need different values of pre - stress in order to substitute a same fluid (LH2 in this case) for different vibration lobed modes.

Once axial stress is found, Young's modulus and mass density of assembly are easily determined from mechanical characteristic curves presented in Fig. 5.

The required axial pre- stress and the mechanical properties for TGM system to substitute the LH2 are shown in Table 3. The analytical results are also compared with numerical results with the help of COMSOL. In FEM simulation, a same model as the one in Section 3.2.1 is built with one difference, the homogenized granular solid is filled in the tank instead of fluids. Both the tank and the granular media are meshed with 2nd order tetrahedral elements using displacements as variables. Only the material properties are different.

The results in Table 3 show the suitability and potential of the proposed methodology for lobed modes. Indeed, we obtain good agreement between the numerical and analytical approaches. More specifically, the numerical results for the TFM and TGM systems agree with the related analytical results. Moreover, by using the Young's modulus $\left(E_{G}\right)$ and mass density $\left(\rho_{G}\right)$ of homogenized solid from Table 3 , we found the good agreement between TFM and TGM systems for different lobed modes in the numerical simulations.

\subsection{Analytical results and comparison with numerical simulation for the vibrations in longitudinal direction}

As discussed in Section 2.4, Young's modulus of granular media evolves enormously during a compression test, hence, the eigenfrequency is increased for each vibration mode. Based on this idea, a methodology similar to the one mentioned in Section 2.1 was proposed to find the required pre-stress that allows substituting the LH2 in vibration analyses.

By applying this strategy, we found that the testing material is too heavy to be able to substitute the LH2 in such a vibration analysis. For example, the eigenfrequency of a tank filled with LH2 is $58.79 \mathrm{~Hz}$ for flexural mode 1 , however, the maximal frequency of a tank filled with the grains used to run the in-lab experiment is only $43.5 \mathrm{~Hz}$ at $90 \mathrm{kPa}$ (See Fig. 8).

This result shows evidence that a lighter material is necessary for flexural modes analysis. In order to analyze and verify the proposed methodology, a "new pseudo-material" with density of $150 \mathrm{~kg} / \mathrm{m}^{3}$ is supposed to take place in the tank.

Fig. 9a and b show two other examples for the flexion modes 1 and 2.

As we can observe on Fig. 9, different values of pre stress needed to be applied on granular materials in order to substitute LH2 for different flexural modes in vibration analysis. For the mode 1, an axial stress of $59,000 \mathrm{~Pa}$ is required, however, a smaller value (equal to $23,000 \mathrm{~Pa}$ ) is necessary for the mode 2 .

In Table 4, analytical and numerical results were compared for the first 4 vibration modes. One observes a good agreement between analytical and numerical results illustrating the suitability of the proposed methodology. It is important to notice that the axial stress applied on granular assembly increases enormously from 0 to $90 \mathrm{kPa}$, however, 


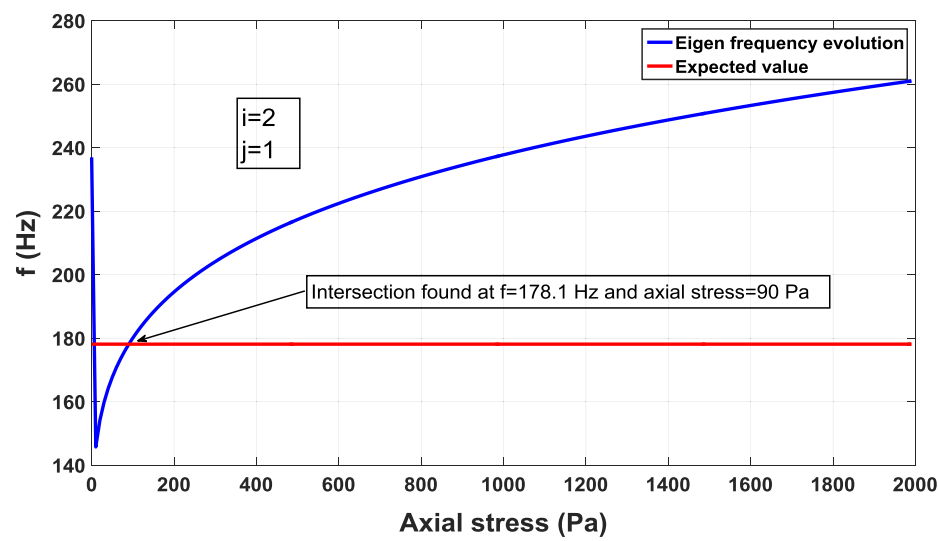

(a)

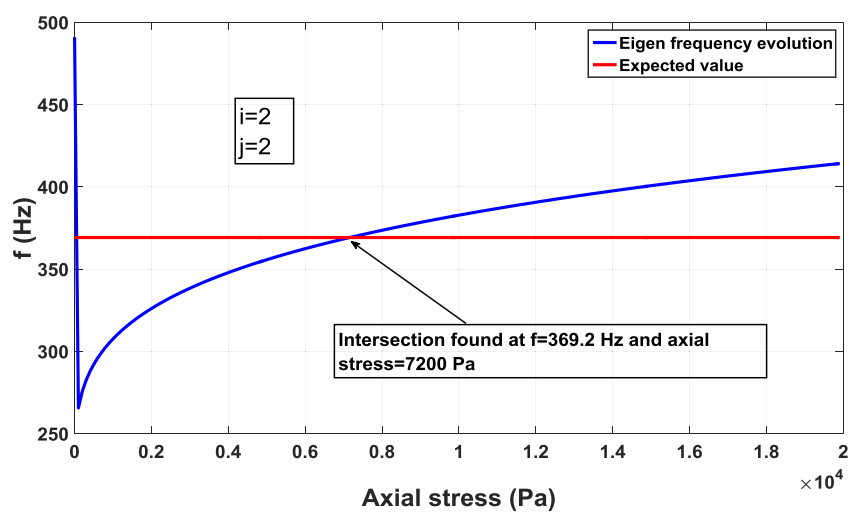

(b)

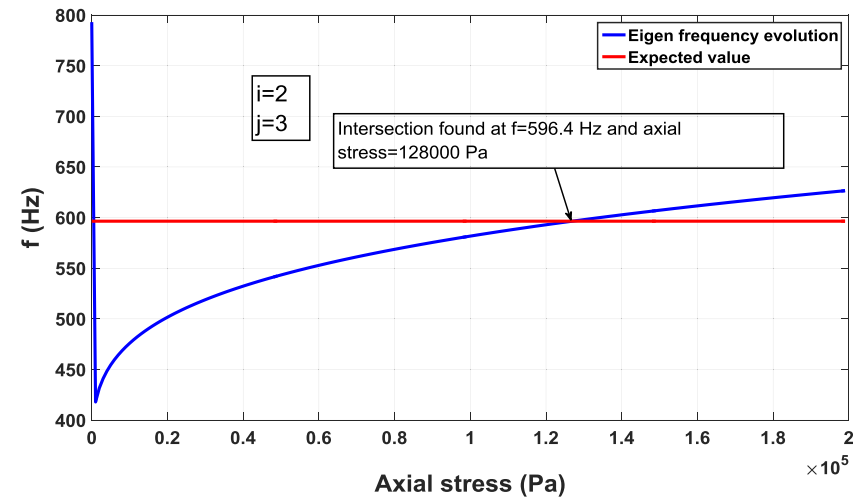

(c)

Fig. 7. Evolution of eigen frequencies with respect to axial stress - determination of required axial pre-stress for lobed modes, with:(a) Mode $(i, j)=(2,1)(b)$ Mode $(i$, $j)=(2,2)(\mathrm{c}) \operatorname{Mode}(i, j)=(2,3)$.

frequency of the TGM system evolves very slightly. For example, for mode 1 , frequency increases $2.6 \%$ (from $57.5 \mathrm{~Hz}$ to $59 \mathrm{~Hz}$ ), for mode 2 , the frequency increases $1 \%$ (from $295 \mathrm{~Hz}$ to $298 \mathrm{~Hz}$ ). This result suggests that, for flexion modes, it is possible to use mechanical properties of one particular mode to study other modes. In other words, this highlights the fact that only one value of pre stress is necessary for vibration analysis. This idea is demonstrated with the following example where the axial stress, Young's modulus and mass density necessary for mode 1 were used to determine the eigenfrequencies of the modes 2,3 and 4 .

By comparing analytical results with the COMSOL numerical simulation in Table 5, we could conclude that only one pre axial stress is required to analyze all flexural vibration modes of cryogenic tank filled with the liquid fuel. This result could explain that, for flexural modes, the mass density of granular assembly contributes a very important role to the global mass of the whole system; on the other hand, the stiffness of grains plays a less important role in the global stiffness of the analyzed system.

We define the contribution of the granular solid system to vibration system in terms of stiffness and mass density as follows:

$P_{G}^{E}=\frac{E_{G} I_{G}}{E_{G} I_{G}+E_{T} I_{T}}(\%)$

$P_{G}^{\rho}=\frac{\rho_{G} A_{G}}{\rho_{G} A_{G}+\rho_{T} A_{T}}(\%)$

with:

- $E_{T} I_{T}, \rho_{T}, A_{T}$ are respectively Young's modulus, inertia moment, mass density and cross section of tank.

- $E_{G} I_{G}, \rho_{G}, A_{G}$ are respectively Young's modulus, inertia moment, mass density and cross section of homogenized granular solid inside the tank.

Table 3

Comparison between analytical and numerical results for tank filled with granular material for lobed modes.

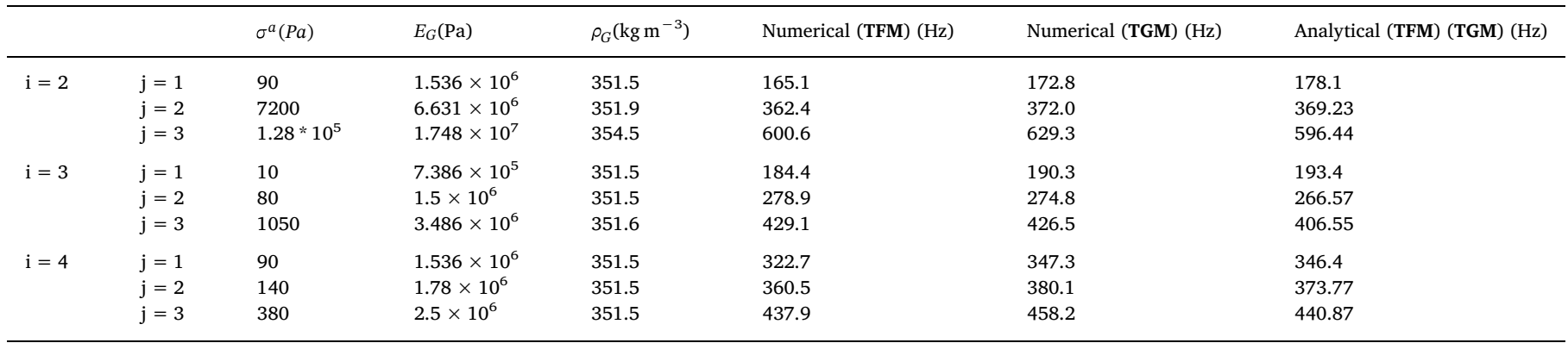




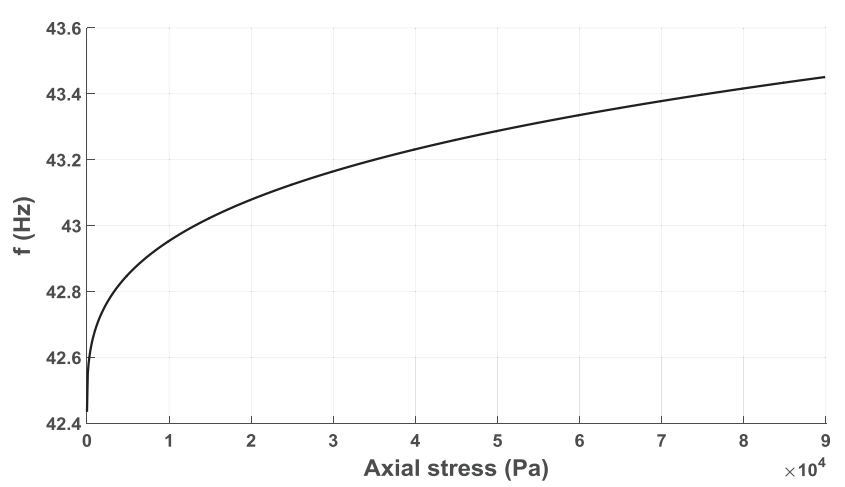

Fig. 8. Evolution of the eigenfrequency with respect to axial stress for the flexural mode 1, using the testing material.

Fig. 10a and b show the evolution of the contribution of the granular solid to the global stiffness and mass. As we can observe, during a compression to $90 \mathrm{kPa}$, the granular assembly contributes only up to $3.5 \%$ of the global stiffness; however, its contribution to the global mass density (per unit length) is always around $54 \%$. This explains why in flexural vibration analysis, we should focus on the mass density of the grains rather than their stiffness.

\section{Conclusion and perspectives}

In this paper, we investigated the potential applicability of a new methodology in aerospace engineering, which may allow the

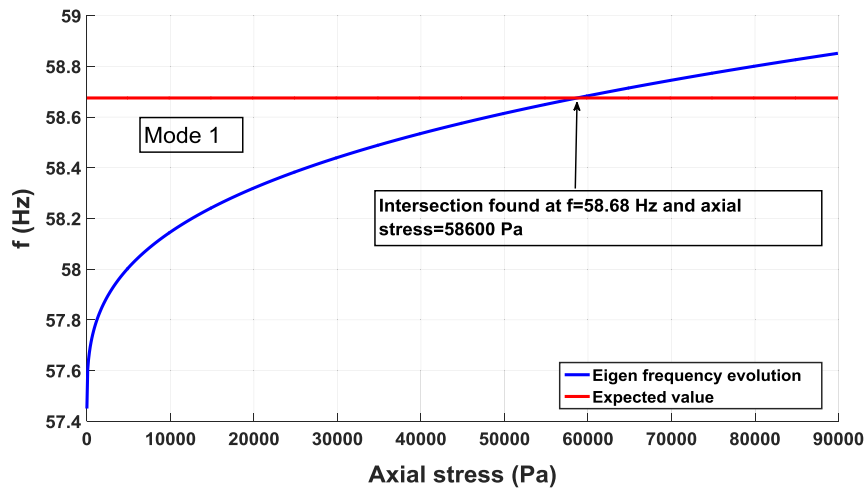

(a) substitution of Liquid Hydrogen in vibration analyses by surrogate granular materials. In general, the mass density and Young's modulus of granular materials evolve during compression, especially for the latter one. For our purpose, mechanical properties of granular materials were determined in our work by a homogenization process. Then, analyses on the vibrations of an empty tank, a tank filled with LH2 and a tank filled with a granular-based material solid were realized.

For the vibration in the tank radial direction (lobed modes), Donnell-Mushtari's shell theory was used in order to find the eigenfrequencies and mode shapes of the vibrating tank. With the presence of a non - compressible fluid such as LH2, the mode shapes remain the same. However, the eigenfrequency of each vibration mode decreases due to the increase in inertia. The vibrations of the homogenized granular material were modeled as the integration of 2D membrane along its length with a shape function. Based on the enormous evolution of the frequencies of the TGM system, we were able to propose an original methodology to substitute fuel liquid in vibration analysis. In this new method, it is necessary to compute the evolution of the eigenfrequency for each mode during compression and find the required pre axial stress which gives the intersection between frequency - stress curve given by TGM system and the expected frequency given by the TFM system. To summarize, for lobed modes, we need different pre stresses for different modes in order to substitute a fluid in vibration analysis. For the flexural modes, Timoshenko's beam theory was used in order to determine the eigenfrequency of each vibration mode. The same methodology as the previous one was proposed to find the required pre stress to substitute the LH2 in vibration analyses. Contrary to the lobed mode case, we only need one value of pre stress in order to

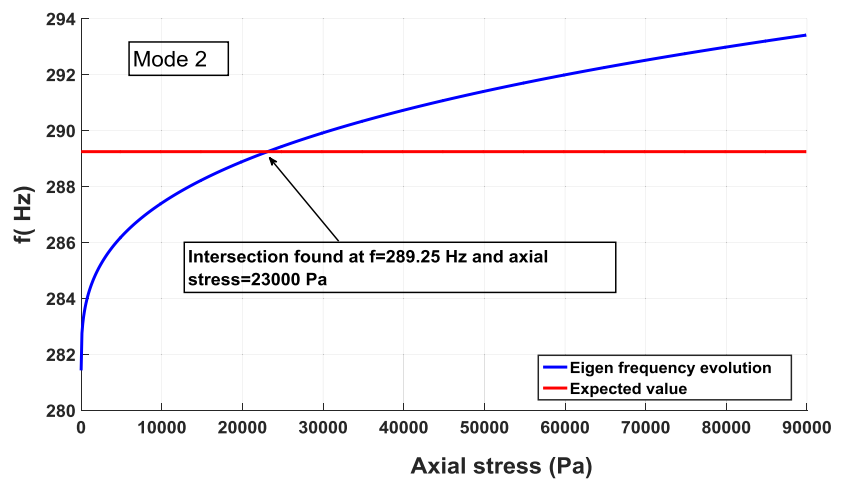

(b)

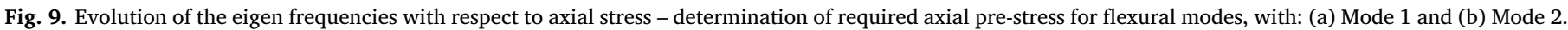

Table 4

Comparison between analytical and numerical results for flexural modes, using different pre - stresses.

\begin{tabular}{|c|c|c|c|c|c|c|}
\hline & Axial stress $(\mathrm{Pa})$ & $E_{G}(\mathrm{~Pa})$ & $\rho_{G}\left(\mathrm{~kg} \mathrm{~m}^{-3}\right)$ & Numerical TFM f (Hz) & Numerical TGM f (Hz) & Analytical TFM TGM f (Hz) \\
\hline Mode 1 & $5.86 \times 10^{4}$ & $1.341 \times 10^{7}$ & 87.90 & 59.7 & 60.00 & 58.68 \\
\hline Mode 2 & $2.3 \times 10^{4}$ & $9.814 \times 10^{6}$ & 87.68 & 300 & 288.40 & 289.25 \\
\hline Mode 3 & $2.17 \times 10^{4}$ & $9.581 \times 10^{6}$ & 87.67 & 664 & 614.20 & 639.01 \\
\hline Mode 4 & 900 & $3.31 \times 10^{6}$ & 87.46 & 993 & 942.60 & 971.89 \\
\hline
\end{tabular}

Table 5

Comparison between analytical and numerical results for flexural modes - Using one pre-stress.

\begin{tabular}{|c|c|c|c|c|c|c|}
\hline & Axial stress $(\mathrm{Pa})$ & $E_{G}(\mathrm{~Pa})$ & $\rho_{G}\left(\mathrm{~kg} \mathrm{~m}^{-3}\right)$ & Numerical TFM f (Hz) & Numerical TGM f (Hz) & Analytical TGM TFM f $(\mathrm{Hz})$ \\
\hline Mode 1 & $5.86 \times 10^{4}$ & $1.341 \times 10^{7}$ & 87.9 & 59.7 & 60.0 & 58.67 \\
\hline Mode 2 & $5.86 \times 10^{4}$ & $1.341 \times 10^{7}$ & 87.9 & 300 & 293.4 & 291.91 \\
\hline Mode 3 & $5.86 \times 10^{4}$ & $1.341 \times 10^{7}$ & 87.9 & 664 & 631.6 & 646.16 \\
\hline Mode 4 & $5.86 \times 10^{4}$ & $1.341 \times 10^{7}$ & 87.9 & 993 & 922.7 & 1005.1 \\
\hline
\end{tabular}




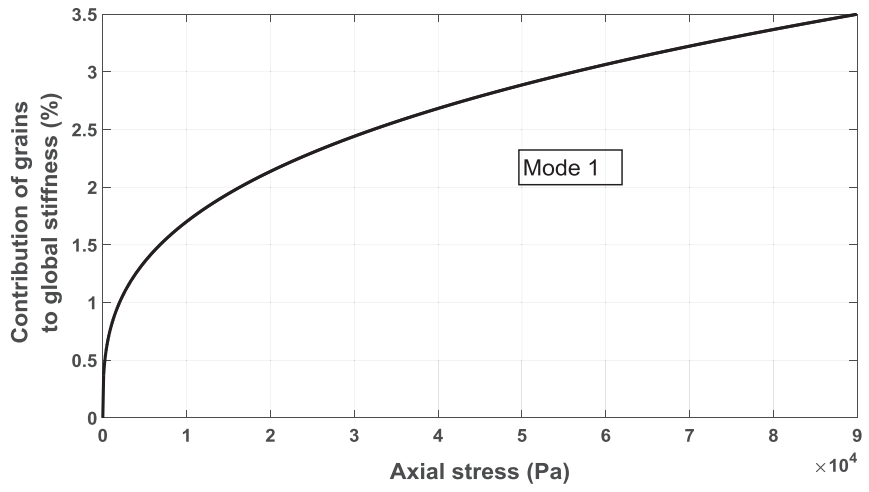

(a)

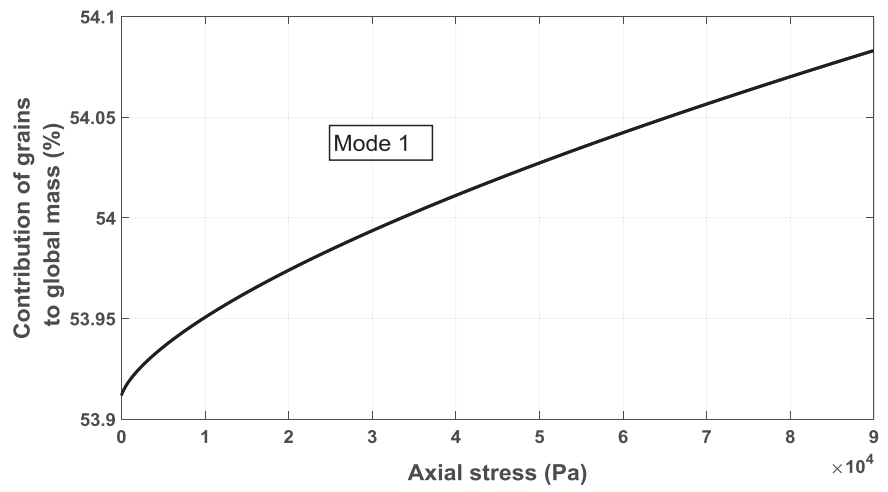

(b)

Fig. 10. Contribution of the granular material to (a) the global stiffness and (b) the global mass during compression.

study all flexural modes. This result was obtained due to the important contribution of granular mass density to global modal mass of the whole system. Analytical results were compared to numerical results simulated with the help of COMSOL. Good agreements between two approaches were found and showed the suitability and potential of the proposed methodology.

This paper also gives an idea of how to choose a surrogate granular material to substitute LH2 in vibration analysis. Based on results presented in Section 3, a material with low mass density should be chosen in order to achieve the flexural modes because eigenfrequencies of these modes depend mostly on mass density of the surrogate materials. Then, the lobed modes can be found by increasing the pre - stresses applied on granular materials.

In the future, it is important to conduct two types of experiment.
The first one focuses on static compression test in order to determine the elastic limit of one particular granular material. The second one focuses on vibration test with tank filled with granular grains. This experiment is important to show agreement between reality, and the analytical and numerical methods.

\section{Acknowledgement}

This research is funded by the Région Midi - Pyrénées, France (research grant FEDER 2014 - 2020). The authors acknowledge the Région Midi-Pyrénées of France for the permission to publish this work. We gratefully thank also the anonymous reviewers for their valuable suggestions and comments which have help us improving this paper.

\section{Appendix A. Identification of parameters $A, B, C$ for Donnell-Mushtafi's shell theory}

Three parameters of Donnell-Mushtari's theory [4] in the Section 2.1.1 are determined from a system of equations mentioned below. By solving these equations, the ratios between the three parameters $(A, B, C)$ can be found from

$\left[\begin{array}{cc}-\lambda^{2}-\frac{1-\vartheta}{2} i^{2}+\Omega^{2} & \frac{1+\vartheta}{2} \lambda i \\ \frac{1+\vartheta}{2} \lambda i & -i^{2}-\frac{1-\vartheta}{2} \lambda^{2}+\Omega^{2}\end{array}\right]\left[\begin{array}{l}A / C \\ B / C\end{array}\right]=\left[\begin{array}{c}-\vartheta \lambda \\ i\end{array}\right]$

with:

$-\lambda=\frac{j \pi R}{L}$

$-\Omega$ : solution of characteristic equation

$\Omega^{6}-K_{2} \Omega^{4}+K_{1} \Omega^{2}-K_{0}=0$

which relies on the following constant parameters

$\left\{\begin{array}{c}K_{2}=1+\frac{1}{2}(3-\vartheta)\left(i^{2}+\lambda^{2}\right)+k\left(i^{2}+\lambda^{2}\right)^{2} \\ K_{1}=\frac{1}{2}(1-\vartheta)\left[(3+2 \vartheta) \lambda^{2}+i^{2}+\left(i^{2}+\lambda^{2}\right)^{2}+\frac{3-\vartheta}{1-\vartheta} k\left(i^{2}+\lambda^{2}\right)^{3}\right] \\ K_{0}=\frac{1}{2}(1-\vartheta)\left[\left(1-\vartheta^{2}\right) \lambda^{4}+k\left(i^{2}+\lambda^{2}\right)^{4}\right]\end{array}\right.$

with $\left(k=\frac{h^{2}}{12 R^{2}}\right)$

By solving Eq. (A1), we found that $\frac{B}{C} \approx \frac{-1}{i}$ for all $(i, j)$, meanwhile the value of $A / C$ varies with different mode shapes. It results finally then that the displacement field can be defined as:

$$
\begin{aligned}
& -u_{i j}=A \cos (i \theta) \cos \left(\frac{j \pi z}{L}\right) \\
& -v_{i j}=-\sin (i \theta) \sin \left(\frac{j \pi z}{L}\right) \\
& -w_{i j}=i \cos (i \theta) \sin \left(\frac{j \pi z}{L}\right)
\end{aligned}
$$

the parameter $A_{i j}$ being determined for each mode and takes the values presented in Table A. 
Table A

Values of parameter A for different lobed modes.

\begin{tabular}{lll}
\hline & & $A_{i j}$ \\
\hline $\mathrm{j}=1$ & $\mathrm{i}=2$ & -0.07175 \\
& $\mathrm{i}=3$ & -0.107186 \\
& $\mathrm{i}=4$ & -0.1049126 \\
$\mathrm{j}=2$ & $\mathrm{i}=2$ & -0.1186 \\
& $\mathrm{i}=3$ & -0.182462 \\
$\mathrm{j}=3$ & $\mathrm{i}=4$ & -0.18858 \\
& $\mathrm{i}=2$ & -0.137115 \\
& $\mathrm{i}=3$ & -0.218632 \\
& $\mathrm{i}=4$ & -0.24155136 \\
\hline
\end{tabular}

Appendix B. Displacement field for 2D membrane in "in-plane" vibration

The components of displacement field and their derivation with respect to the radial direction for a 2D membrane in "in-plane" vibration (Section 2.2.3) were proposed by Kim et al [20].

$U_{r}=\frac{1}{2}\left\{A_{1}\left(J_{i+1}(\lambda \xi)-J_{i-1}(\lambda \xi)\right)+A_{2}\left(J_{i+1}(c \lambda \xi)+J_{i-1}(c \lambda \xi)\right)\right\}$

$U_{\theta}=\frac{1}{2}\left\{A_{1}\left(J_{i+1}(\lambda \xi)+J_{i-1}(\lambda \xi)\right)+A_{2}\left(J_{i+1}(c \lambda \xi)-J_{i-1}(c \lambda \xi)\right)\right\}$

$\dot{U}_{r}=\frac{1}{4}\left\{\lambda A_{1}\left[2 J_{i}(\lambda \xi)-J_{i+2}(\lambda \xi)-J_{i-2}(\lambda \xi)\right]+c \lambda A_{2}\left[J_{i-2}(c \lambda \xi)-J_{i+2}(c \lambda \xi)\right]\right\}$

$\dot{U}_{r}=\frac{1}{4}\left\{\lambda A_{1}\left[J_{i-2}(\lambda \xi)-J_{i+2}(\lambda \xi)\right]+c \lambda A_{2}\left[2 J_{i}(c \lambda \xi)-J_{i+2}(c \lambda \xi)-J_{i-2}(c \lambda \xi)\right]\right\}$.

Here $A_{1}$ and $A_{2}$ are two variables that are linked by the equation:

$D_{22} D_{12} A_{2}=A_{1} D_{11} D_{21}$

while

$D_{11}=-\frac{\lambda}{2}\left[J_{i+2}(\lambda)+J_{i-2}(\lambda)-2\left(c^{2}-1\right) J_{i}\left(J_{i+2}(\lambda)\right)\right]$

$D_{22}=-\frac{c \lambda}{2}\left[J_{i+2}(c \lambda)+J_{i-2}(c \lambda)\right]$

$D_{22}=-\frac{c \lambda}{2}\left[J_{i+2}(c \lambda)-J_{i-2}(c \lambda)\right]$

$D_{22}=-\frac{\lambda}{2}\left[J_{i+2}(\lambda)-J_{i-2}(\lambda)\right]$

In those equations, $c$ is the variable which depends on the Poisson's ratio of the homogenized granular material by the following equation:

$c=\sqrt{\frac{2}{1-\vartheta_{G}}}$

and $\lambda$ is the variable which depends on the mechanical properties and the vibration frequency of the homogenized granular material by following equation

$\lambda=2 \pi f \sqrt{\frac{\rho_{G}\left(1-\vartheta^{2}\right)}{E_{G}}}$

The vibration frequency of each mode is found by solving the characteristic equation:

$2 J_{i+1}(\lambda) J_{i-2}(c \lambda)+2 J_{i+2}(c \lambda) J_{i-2}(\lambda)-2\left(c^{2}-1\right) J_{i}(\lambda)\left\{J_{i+2}(c \lambda)+J_{i-2}(c \lambda)\right\}=0$

Appendix C. Variables of Timoshenko's beam theory

The parameters $\alpha, \beta, R_{1}, R_{2}, R_{3}, R_{4}, R_{1}^{\prime}, R_{2}^{\prime}, R_{3}^{\prime}, R_{4}^{\prime}$ in the Section 2.3 are calculated with the following expressions [6]:

$\alpha=\frac{1}{\sqrt{2}}\left\{-\left(r^{2}+s^{2}\right)+\left[\left(r^{2}-s^{2}\right)^{2}+\frac{4}{b^{2}}\right]^{2}\right\}^{2}$

$\beta=\frac{1}{\sqrt{2}}\left\{\left(r^{2}+s^{2}\right)+\left[\left(r^{2}-s^{2}\right)^{2}+\frac{4}{b^{2}}\right]^{2}\right\}^{2}$ 
$R_{1}=\frac{b}{\alpha} \sinh (b \alpha)+\frac{M}{M_{b}} b^{2} \cosh (b \alpha)$

$R_{2}=\frac{b}{\alpha} \cosh (b \alpha)+\frac{M}{M_{b}} b^{2} \sinh (b \alpha)$

$R_{3}=\frac{b}{\beta} \sin (b \beta)+\frac{M}{M_{b}} b^{2} \cos (b \beta)$

$R_{4}=-\frac{b}{\beta} \cos (b \alpha)+\frac{M}{M_{b}} b^{2} \sin (b \alpha)$

$R_{1}^{\prime}=\frac{\alpha^{2}+s^{2}}{\alpha}\left\{b \alpha \cosh (b \alpha)-0.5 * \frac{M}{M_{b}} \sigma^{2} b^{2} \sinh (b \alpha)\right\}$

$R_{2}^{\prime}=\frac{\alpha^{2}+s^{2}}{\alpha}\left\{b \alpha \sinh (b \alpha)-0.5 * \frac{M}{M_{b}} \sigma^{2} b^{2} \cosh (b \alpha)\right\}$

$R_{3}^{\prime}=-\frac{\beta^{2}-s^{2}}{\beta}\left\{b \beta \cos b \beta-0.5 * \frac{M}{M_{b}} \sigma^{2} b^{2} \sin (b \beta)\right\}$

$R_{4}^{\prime}=\frac{\alpha^{2}+s^{2}}{\alpha}\left\{b \beta \sin (b \beta)-0.5 * \frac{M}{M_{b}} \sigma^{2} b^{2} \cos (b \beta)\right\}$

with $r^{2}=\frac{I}{A L^{2}}, s^{2}=\frac{E I}{K A G L^{2}}$ and $\sigma=\frac{k}{L}$.

The initial boundary value problems for a homogeneous and linear elastic beam that is clamped at its left extremity and loaded by a mass $\mathrm{M}$ at its right extremity is:

$-y=0$ at $z=0$

$-\varphi=0$ at $z=0$

$-K G A\left(\varphi-\frac{\partial y}{\partial z}\right)-M \frac{\partial^{2} y}{\partial t^{2}}=0$ at $z=L$

$-E I \frac{\partial \varphi}{\partial z}+I \frac{\partial^{2} \varphi}{\partial t^{2}}=0$ at $z=L$ with $I=\frac{1}{2} M k^{2}(k$ : gyration radius).

\section{Appendix D. Dimension and mechanical properties of granular grains}

The sample in the Section 3.1 contains 35000 grains made of epoxy with mineral charges. The radius of all grains is around $1.665 \mathrm{~mm}$, the specific weight of each grain is $6.03 .10^{-4} \mathrm{~g} / \mathrm{mm}^{3}$. The Young's modulus $\left(E_{m}\right)$ and Poisson's ratio $\left(\vartheta_{m}\right)$ are respectively equal to $600 \mathrm{Mpa}$ and 0.015 . The method used to identify the mechanical properties of each grain is detailed in [8]. Details of grain properties are shown in the Table D.

Table D

Geometric and mechanical mean properties of the grains.

\begin{tabular}{ll}
\hline Number of grains & 35000 \\
Radius & $1.665 \mathrm{~mm}$ \\
Specific weight & $6.03 .10^{-4} \mathrm{~g} \mathrm{~mm}^{-3}$ \\
$E_{m}$ & $600 \mathrm{MPa}$ \\
$\vartheta_{m}$ & 0.015 \\
\hline
\end{tabular}

\section{References}

[1] Sutton GP, Biblarz O. Rocket propulsion elements. John Wiley \& Sons, Inc; 2010

[2] Ivey EW. Mated vertical ground vibration test. National Aeronautics and Space Administration; 1980.

[3] Chiambaretto PL, Charlotte M, Morlier J, Villedieu P, Gourinat Y. Surrogate granular for modal test of fluid filled tank. In: Special topics in structural dynamics, conference proceedings of the society for experimental mechanics. vol. 6; 2016

[4] Leissa AW. Vibration of shells. National Aeronautics and Space Administration; 1993.

[5] Axisa F, Antunes J. Modelling of mechanical systems: fluid-structure interaction. Oxford: Butterworth-Heinemann; 2006.

[6] Bruch Jr. JC, Mitchell TP. Vibrations of a mass - loaded clamped- free Timoshenko beam. J Sound Vib 1987;114(2):341-5.

[7] Han SM, Benaroya H, Wei T. Dynamics of transversely vibrating beams using four engineering theory. J Sound Vib 1999;225(5):935-88.

[8] Grippon E, Legaud T, Chiambaretto PL, Fascio V, Gourinat Y, Lapoujade V. Guideline of a metamaterial for launcher tanks dynamic experiments. In: Proceedings of 14th european conference on spacecraft structures, materials \& environmental testing (ECSSMET14) Toulouse; 2016.

[9] Hertz H. Uber die berührung fester elastischekorper (On Contact Between Elastic Bodies). J Reiner Angew Mathematik 1882;92:156-71.

[10] Cundall PA, Strack ODL. A discrete numerical model for granular assemblies.
Geotechnique 1979;29(1):47-65.

[11] Emeriault F, Cambou B. Micromechanical modeling of anisotropic non-linear elastic of Granular medium. Int J Solids Struct 1996;33(18):2591-607.

[12] Chang S, Sundaram SS, Misra A. Initial moduli of particulated mass with frictional contacts. Int J Numerical Anal Methods Geomechanics 1989;13:629-44.

[13] Smith W0, Foote PD, Busang PF. Packing of homogeneous spheres. Phys Rev 1929;34:1271-4.

[14] Yanagisawa E. Influence of void ratio and stress condition on the dynamic shear modulus of granular media. Adu Mech Flow Granular Mater 1983;2:947-60.

[15] Field WG. Towards the statistical definition of a granular mass. In: Proc 4th Aust and NZ Cont on Soil Mech; 1963. p. 143-8.

[16] Comsol user's manual; 2011.

[17] Paidoussis M. Fluid Structure interactions: slender structures and axial flow. 2nd ed. 2014. p. Elsevier.

[18] Paidoussis M. Fluid Structure interactions: slender structures and axial flow. 2nd ed. Elsevier; 2016.

[19] Morand HJ-P, Ohayon R. Fluid - structure interaction. Wiley; 1995.

[20] Kim CB, Cho HS, Beom HG. Exact solutions of in-plane natural vibration of a circular plate with outer edge restrained elastically. J Sound Vib 2012;331(9):2173-89.

[21] McCarty R. Hydrogen technology survey: thermophysical properties. Technical report. National Aeronautics and Space Administration; 1975. 